\title{
Dönüşüm faktörünü kullanarak nokta yükü dayanım indeksinden bazaltların tek eksenli basınç dayanımının tahmini
}

\author{
Prediction of the uniaxial compressive strength of basalts from the point load strength index \\ using the conversion factor
}

\author{
OUmar YOUSSOUF MAHAMAT TAHIR ${ }^{1, a}$, Kadir KARAMAN*1,b \\ ${ }^{1}$ Karadeniz Teknik Üniversitesi, Mühendislik Fakültesi, Maden Mühendisliği Bölümü, 61080, Trabzon
}

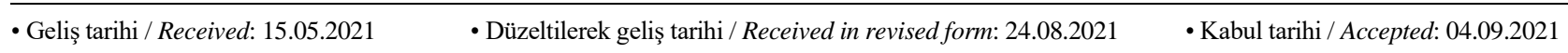

\begin{abstract}
Öz
Dönüşüm faktörü (k) nokta yükü dayanım indeksi (PLI) ile tek eksenli basınç dayanımı (UCS) arasındaki oran olup kayaçların UCS tahmininde 60 senedir kullanılmaktadır. Birçok araştırmacı magmatik, metamorfik ve tortul gibi farklı jeolojik kökenlerdeki kayaçlar için UCS ve PLI arasındaki ilişkiyi araştırmıştır. Bazı çalışmalarda ise magmatik (piroklastik, volkanik, plütonik), tortul (kimyasal ve kırıntılı) ve metamorfik kayaçların (foliasyonlu ve foliasyonsuz) alt kökenlerine ilişkin k katsayıları araştırılmışıı. Literatür taramasına göre $\mathrm{k}$ katsayısı şeyl, kumtaşı ve kireçtaşı gibi bazı kayaçlar için yeterince çalışılmış olsa da bazaltlarda sınırlı sayıda çalışılmış̧ır. Bu çalışmanın amacı $\mathrm{k}$ katsayısının bazaltlar için değişimini bölgesel ve global açıdan incelemektir. $\mathrm{k}$ değerleri sıfır kesişim basit regresyon analizi ve UCS/PLI oranından elde edilmiştir. Bu çalışmada, bazaltlar için en uygun $\mathrm{k}$ oranı aralığının $17 \leq \mathrm{k} \leq 20$ olması gerektiği tavsiye edilmiştir. Tek bir değer vermek gerekirse, ANOVA sonuçlarına göre k değerinin 19 olması uygun olacaktır.
\end{abstract}

Anahtar kelimeler: Dönüşüm faktörü, Nokta yükü dayanım indeksi, Tek eksenli basınç dayanımı

\begin{abstract}
Conversion factor $(k)$, the ratio between point load strength index (PLI) and uniaxial compressive strength (UCS), has been used for 60 years in UCS estimation of rocks. Many researchers have investigated the relationship between UCS and PLI for various rock types of different geological origins, such as igneous, sedimentary, and metamorphic rocks. The $k$ values for subclasses of igneous (pyroclastic, volcanic, and plutonic), sedimentary (chemical and clastic), and metamorphic (foliated and nonfoliated) rocks were investigated in some studies. According to the literature review, although the k has been studied sufficiently for some rocks such as shale, sandstone and limestone, it has been studied in a limited number of basalts. The aim of this study is to examine the variation of $k$ for basalts from a regional and global perspective. The $k$ values were obtained by zero-intercept simple regression analysis and the UCS/PLI ratio. In this study, it is suggested that the optimal $k$ ratio should be in the range of $17 \leq k \leq 20$ for the basalts. To give a single value, it would be appropriate for $k$ to be 19 according to the ANOVA results.
\end{abstract}

Keywords: Conversion factor, Point load strength index, Uniaxial compressive strength

\footnotetext{
*b Kadir KARAMAN; kadirkaraman@ktu.edu.tr, Tel: (0462) 377 42 64, orcid.org/ 0000-0002-3831-4465

${ }^{a}$ orcid.org/0000-0002-3004-267X
} 


\section{Giriş}

Kaya malzemesinin tek eksenli basınç dayanımı (UCS) maden, jeoloji ve inşaat mühendisleri için önemli bir parametre olup şev duraylılığından tünel gibi yeraltı açıklıklarının tasarımına kadar geniş bir yelpazede kullanılmaktadır. UCS, hem Uluslararası Kaya Mekaniği Birliğgi (ISRM) hem de Amerikan Test ve Malzemeler Birliği (ASTM) tarafindan önerilen yöntemlere göre belirlenebilmektedir. Ancak, UCS parametresinin doğrudan belirlenmesi mühendislik çalışmaların ön aşamasında nispeten pahalı, zahmetli ve zaman alıc1 olabilmektedir (Kaya ve Karaman, 2016). Ayrıca, bazı kaya kütlelerinden (ince tabakalı, zayıf, çok çatlaklı kayalar vb.) standartlarca önerilen yüksek kaliteli NX çaplı karot örnekler elde etmek oldukça güçleşmektedir. $\mathrm{Bu}$ nedenlerden dolayı UCS parametresinin doğrudan belirlenemediği durumlarda daha ucuz ve pratik olan PLI gibi indeks deneylerden tahmin edilmektedir (D'Andrea vd., 1964; Bieniawski, 1975; Kahraman, 2001; Fener vd., 2005; K1lıç ve Teymen 2008; Singh vd., 2012; Kahraman, 2014; Karaman vd., 2015a; Karaman vd., 2015b; Kaya ve Karaman, 2016; Akbay ve Altındağ, 2020). Birçok araştırmacı UCS ile PLI arasındaki orandan elde edilen dönüşüm faktörünü (k) farklı kayaçlar için araştırmıştır. Broch ve Franklin (1972) ve Bieniawski (1975) sırasıyla k katsayısının 24 ve 23 olduğunu ifade etmişlerdir. Pells (1975) k değerinin 24 olarak kabul edilmesi durumunda dolorit, norit ve piroksenit gibi kayaçların UCS tahmininde $\% 20$ hataya yol açtığını ifade etmiştir. Benzer şekilde Topal (2000) $\mathrm{k}$ değerinin 24 alınmasının hatalı olduğunu ve tüf gibi zayıf kayaçlar için bu oranın 20'nin altında ve 13-14 gibi bir değerde olduğunu vurgulamıştır. Read vd., (1980) k değerinin kaya türüne ve ayrışmaya bağl1 olarak değişiklik gösterdiğini ifade etmişlerdir. Kaya ve Karaman (2016) tarafindan 490 gibi oldukça fazla sayıda veri kullanılarak piroklastik, volkanik ve plütonik gibi magmatik, kimyasal ve kırıntılı gibi tortul ve foliasyonlu ve foliasyonsuz gibi metamorfik kayaçların alt kökenlerine yönelik $\mathrm{k}$ katsayıları araştırılmış ve araştırmacılar $\mathrm{k}$ değerlerinin 12.98 ile 18.55 arasında değiştiğini ifade etmişlerdir.

$\mathrm{Bu}$ konuda yapılmış çalışmalar tarandığında $\mathrm{k}$ katsayısı şeyl, kumtaşı ve kireçtaşı gibi bazı kayaçlar için yeterince çalışılmış olsa da, söz konusu katsayının bazaltlarda oldukça sınırlı sayıda çalışıldığı görülmektedir. Yapılan çalışmalara göre, tüm kaya malzemesi için tek bir $\mathrm{k}$ değerinin uygulanamayacağ 1 ve bu değerin farklı kaya türleri ve kökenleri için oldukça geniş aralıkta değiştiği görülmektedir (Kahraman, 2014). Topal
(2000) gelecekte yapılacak araştırma ve uygulamalarda değişik kaya türleri için ayrı ayrı kullanılabilecek k oranları bulunmasını önermiştir. Sharo ve Al-Tahawa (2019) kayaçların UCS ve diğer jeomekanik özellikleri arasında çok sayıda ilişki kurulmasına rağmen, bazaltlarda hala UCS ve diğer parametreler arasında eşitlik geliştirmeye ihtiyaç olduğundan bahsetmişlerdir. Bu çalışmada fiziko-mekanik özelliklerinde önemli farklılık gözlenen ve aynı zamanda mühendislik uygulamalarında (agrega, beton, micir, yol çalışmaları vb.) yaygın olarak kullanılan bazalt kayaçları için $\mathrm{k}$ katsayısının belirlenmesi amaçlanmıştır.

\section{Materyal ve metot}

Bu çalışmada Trabzon İlinden 4 adet ve Ordu İlinden 1 adet olmak üzere toplam 5 farklı bazalt örneği kullanılmıştır (Şekil 1). UCS ve PLI deneyleri ISRM (2007) tarafindan önerilen yöntemlere göre yapılmıştır. Standartlara uygun karot örneklerinin alınabilmesi için, sahada her blok örneğinin makroskopik incelemesi yapılarak ayrışma ve kırık, çatlak gibi süreksizlik içermeyen örnekler seçilmiştir. Deneyler taze ve sağlam karot örnekleri üzerinde gerçekleşmiştir.

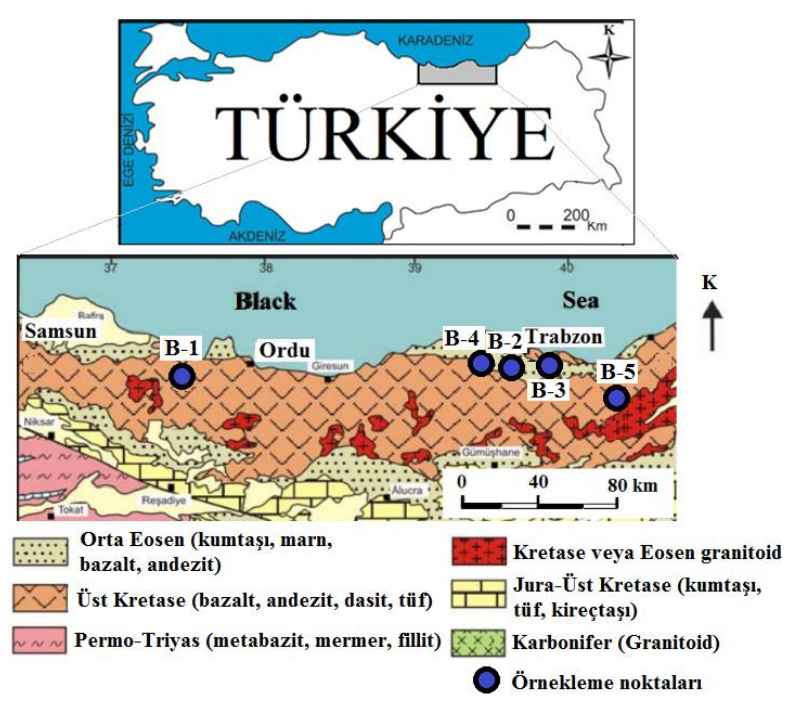

Şekil 1. Örnekleme noktaları ve jeolojik bilgiler (Okay ve Sahinturk (1997) ve Parlak vd. (2013)'ten değiştirilmiştir)

\subsection{Tek eksenli basınç dayanımı}

UCS deneylerinde boy/çap oranı en az 2.5 olan NX çaplı $(5.47 \mathrm{~cm})$ karot örnekler kullanılmıştır. Deneyler, 300 ton kapasiteli bilgisayar kontrollü hidrolik pres ile yükleme hızı $0.75 \mathrm{MPa} / \mathrm{s}$ olacak şekilde yapılmıştır. Her kaya örneği için 5 adet karot deneye tabi tutulmuş ve ortalama değer UCS olarak kaydedilmiştir. 


\subsection{Nokta yükü dayanım indeksi}

$\mathrm{Bu}$ çalışmada, eksenel PLI yöntemine göre boy/çap oranı $0.50-0.55$ olan karot örnekler kullanılmıştır. Dijital nokta yükü deney aleti kullanılmış olup, yenilmenin $10-60$ saniyede gerçekleşmesi sağlanmıştır. Her kaya için 10'ar adet örnek olmak üzere toplam 50 adet karot örneğinde deney yapılmıştır. En yüksek ve en düşük iki sonuç ortalamaya dahil edilmemiş olup, geriye kalan 6 değerin ortalaması dikkate alınmıştır. Nokta yükü dayanım indeksi aşağıdaki eşitlik kullanılarak hesaplanmıştır.

$I_{s}=P / D e^{2}$

Eşitlikte; $\mathrm{I}_{\mathrm{s}}$ : Düzeltilmemiş nokta yük dayanım indeksi (MPa), P: Örneği kıran kuvvet (kN), De: Eşdeğer karot çapı (cm)'dir.

Karot örneklerde çapsal yükleme için $D e^{2}=D^{2}$, eksenel ve şekilsiz örnekler üzerinde yapılan deneylerde ise $D^{2}=4 \mathrm{~A} / \pi$ olarak alınmaktadır. Burada; $\mathrm{A}=\mathrm{WxD}$; konik başlıkların temas noktalarından geçen örneğin en küçük kesit alanıdır. Eğer konik uçların örneğin içine girmesi durumu söz konusu ise; $A=W D$ olarak alınır. $B u$ eşitliklerde, W genişlik $(\mathrm{cm}), \mathrm{D}$ ise yükleme noktaları arasındaki uzaklıktır. Yukarıda ifade edilen düzeltilmemiş nokta yük dayanımı değeri referans çapa $(D=50 \mathrm{~mm})$ göre düzeltmek için aşağıdaki eşitlikler kullanılmıştır.

$\mathrm{I}_{\mathrm{s}(50)}=\mathrm{F} \times \mathrm{I}_{\mathrm{s}}$

$\mathrm{F}=(\operatorname{De} / \mathrm{A})^{0.45}$

Eşitlikte;

$\mathrm{I}_{\mathrm{S}(50)}: 50 \mathrm{~mm}$ çaplı karota göre düzeltilmiş nokta yük dayanımı (MPa),

F: Boyut düzeltme faktörüdür.

\section{Bulgular ve tartışma}

\subsection{Verilerin değerlendirilmesi}

İlk olarak UCS tahmini için her bir örnek grubuna ait ortalama UCS ve PLI değerleri arasında sifirkesişim basit regresyon analizleri yapılmış (Şekil 2) ve k katsayıları belirlenmiştir. Daha sonra UCS/PLI oranından elde edilen $k$ değerleri bulunmuştur (Tablo 1). Sifir-kesişim regresyon analizine göre k katsayısı 17.3, UCS/PLI oranından elde edilen ortalama $\mathrm{k}$ değeri ise 16.9 olarak elde edilmiştir. Her iki yöntemden elde edilen $k$ değerinin aritmetik ortalaması 17.1 olarak hesaplanmıştır.

Tablo 1. Regresyon analizleri ve UCS/PLI oranından elde edilen k katsayıları

\begin{tabular}{cccccc}
\hline Örnek no & UCS (MPa) & PLI (MPa) & Regresyon & UCS/PLI & Aritmetik ortalama k \\
\hline B-1 & 182.0 & 10.06 & 17.3 & 18.1 & \\
B-2 & 166.4 & 9.08 & 17.3 & 18.3 & \\
B-3 & 71.13 & 4.3 & 17.3 & 16.5 & \\
B-4 & 111.6 & 7.2 & 17.3 & 15.5 & \\
B-5 & 126 & 7.8 & 17.3 & 16.2 & $\mathbf{1 7 . 1}$ \\
& Ortalama k & & $\mathbf{1 7 . 3}$ & $\mathbf{1 6 . 9}$ & \\
\hline
\end{tabular}

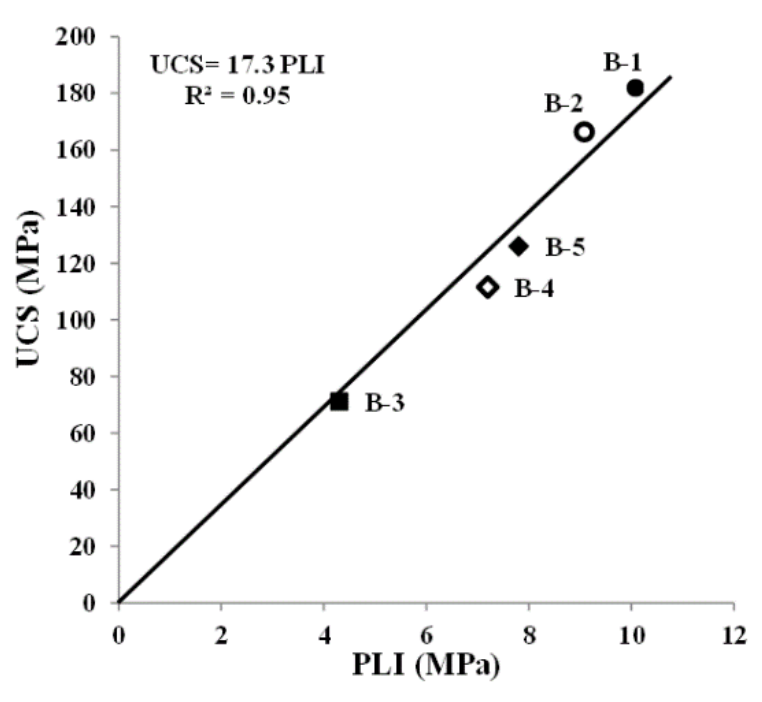

Şekil 2. UCS ve PLI arasındaki ilişki
Read vd. (1980) bazaltlarda ayrışma ve boşluk oranlarındaki değişimin k katsayısı üzerine etkisini araştırdıkları çalışmada boşluk oranı arttıkça $\mathrm{k}$ katsayısının 7.5'lere kadar düştüğünü, sağlam bazalt için ise bu oranın 18'e kadar çıktığını ifade etmişlerdir. Aggistalis vd. (1996) ayrışma oranlarına bağlı olarak bazalt ve gabro kayaçlarının UCS parametresini PLI gibi dolaylı yöntemlerden tahmin etmiştir. Endait ve Juneja (2015) bazaltların doygun ve kuru durumları için $\mathrm{k}$ katsayısını doygun durum için 18 ve kuru durum için 24 olarak bulmuşlardır. Sharo ve Al-Tahawa (2019) Ürdün bazaltları için $\mathrm{k}$ değerlerini 23.52 olarak bulmuşlardır (Tablo 2). Bu çalışmada ise taze bazaltlar için $\mathrm{k}$ katsayısı araştırılmıştır. $\mathrm{Bu}$ çalışmadan elde edilen veriler ile literatürden toplam 108 adet UCS - PLI veri çiftleri (Tablo 3) 
kullanılarak genel bir değerlendirme yapılmıștır (Şekil 3). Tablo 2'deki araştırmacıların kullandıkları verilerin bir kısmı paylaşılmadığı için değerlendirmeye alınamamıştır.

Tablo 2. Literatürde bazaltlar için önerilen $\mathrm{k}$ değerleri

\begin{tabular}{llll}
\hline Kaya türü & Eşitlik & Referans \\
\hline Bazalt & UCS=18 PLI & Read vd., (1980) \\
& UCS=21.96 PLI & Aggistalis & vd., \\
Bazalt & & (1996) & \\
Bazalt & UCS=18 PLI & Endait ve Juneja \\
(doygun) & & $(2015)$ & \\
Bazalt & UCS=24 PLI & Endait ve Juneja \\
(kuru) & & $(2015)$ & \\
& UCS=23.52 PLI & $\begin{array}{l}\text { Sharo ve Al- } \\
\text { Tahawa }(2019)\end{array}$ \\
\hline
\end{tabular}

Şekil 3 dikkate alındığında 108 adet $\mathrm{k}$ değerlerinin genellikle $15-25$ aralığında değiştiği görülmektedir. Öte yandan Raj ve Pedram (2015) ve Endait ve Juneja (2015) tarafindan yapılan çalışmaya ait $\mathrm{k}$ değerleri literatür ile bağdaşmayacak ölçüde yüksektir. Raj ve Pedram (2015) çalışmasından elde edilen k oranları 59 118 arasında değişirken, Endait ve Juneja (2015) çalışmasından elde edilen $\mathrm{k}$ oranları ise $5-330$ arasında değişmektedir. Ancak bütün verilerin değerlendirildiği sıfir kesişim basit regresyon analizi yapıldığında ise $\mathrm{k}$ değeri yaklaşı 20 çıkmaktadır. Raj ve Pedram (2015) çalışmasındaki bazaltlara ait sıfır kesişim basit regresyon analizi yapıldığında ise $\mathrm{k}$ değeri yaklaşık 85 çıkmaktadır. Kahraman vd., (2005) farklı araştırmacılar tarafindan sıfır-kesişim regresyon eşitlikleri kullanarak önerilen k katsayılarının 8.6-29 gibi geniş bir aralıkta değişim gösterdiğini vurgulamıştır. $\mathrm{Bu}$ nedenle $\mathrm{k}$ katsayılarının 8-30 arasında değişim gösterdiği ve verilerin büyük çoğunun bu aralıkta yer aldığı 84 adet veri çifti çoklu karşılaştırma amaciyla kullanılmıştır. Söz konusu veri çiftlerinden 8 tanesi Metabazalt kayaçlarına aittir. Dayanım arttıkça k değerlerinin arttı̆g 1 bilinmektedir. Bununla beraber bazaltlarda dayanım artışının $\mathrm{k}$ değerleri üzerinde bir etkisinin olmadığg görülmüştür (Şekil 3).

Tablo 3. Bu çalışma ve literatürden bazaltlara yönelik derlenen veriler

\begin{tabular}{lllll}
\hline Araştırmacilar & $\begin{array}{l}\text { UCS (MPa) } \\
\text { En düşük }\end{array}$ & $\begin{array}{l}\text { UCS (MPa) } \\
\text { En yüksek }\end{array}$ & $\begin{array}{l}\text { PLI (MPa) } \\
\text { En düşük }\end{array}$ & $\begin{array}{l}\text { PLI (MPa) } \\
\text { En yüksek }\end{array}$ \\
\hline Panek ve Fannon (1992)* & - & 175.2 & - & 11.99 \\
Aggıstalıs vd. (1996) & 43.08 & 91.21 & 1.005 & 3.33 \\
Kilıç vd. (2003)* & - & 86.2 & - & 4.28 \\
Y1ldız vd. (2008) & 79.56 & 140.88 & 3.832 & 7.301 \\
Kilıç ve Teymen (2008)* & - & 131.0 & - & 4.0 \\
Karaman ve Kesimal (2015) & 47.0 & 202.0 & 2.9 & 10.3 \\
Raj ve Pedram (2015) & 39.08 & 215.39 & 0.36 & 2.64 \\
Endait ve Juneja (2015) & 2.2 & 163.1 & 0.1 & 9.1 \\
Karaman vd. (2015a) & 34.0 & 197.0 & 2.76 & 9.95 \\
Özdemir ve Sarıc1 (2019)* & - & 126.2 & - & 8.94 \\
Şahin vd. (2020) & - & 84.44 & - & 8.39 \\
Bu çalışma & 71.13 & 182.0 & 5.3 & 11.1 \\
\hline
\end{tabular}

*Tek veri

\section{2. Ölçülen ve tahmini UCS değerlerinin çoklu karşılaştırılması}

Varyans analizi (ANOVA, Analysis of variances), iki veya daha fazla verilerin grup ortalamalarının veya işlem ortalamalarının farklılığını test etmek için yararlanılan bir yöntemdir (Kalayc1, 2009). Bu çalışmada ANOVA türlerinden tek yönlü varyans analizi (Oneway ANOVA) kullanılmıştır. Grupların homojen olması için anlamlılık seviyesi (P) $>0.05$ olmasi gerekmektedir. Gruplar homojen olmadığında ise $(\mathrm{P}<0.05)$ homojen olmayan varyans analizleri (Tamhane's T2, Dunnett's T3, Games-Howell) yapilmaktadir. Daha sonra homojenlik durumuna göre bir yöntem seçilerek analiz yapılır ve ilk olarak ANOVA tablosundaki $P$ (anlamlılık seviyesi) değerine bakılır. Eğer bu teste göre $\mathrm{P}<0.05$ ise "grup ortalamaları birbirinden önemli düzeyde farklıdır" veya "grup ortalamalarından en az biri diğerlerinden farklıdır" yorumları yapılmaktadır (Dunnett ve Tamhane, 1992). $P>0.05$ ise gruplar birbirinin aynıdır veya grup ortalamaları birbirinden farklı değildir anlamı çıkmaktadır. 


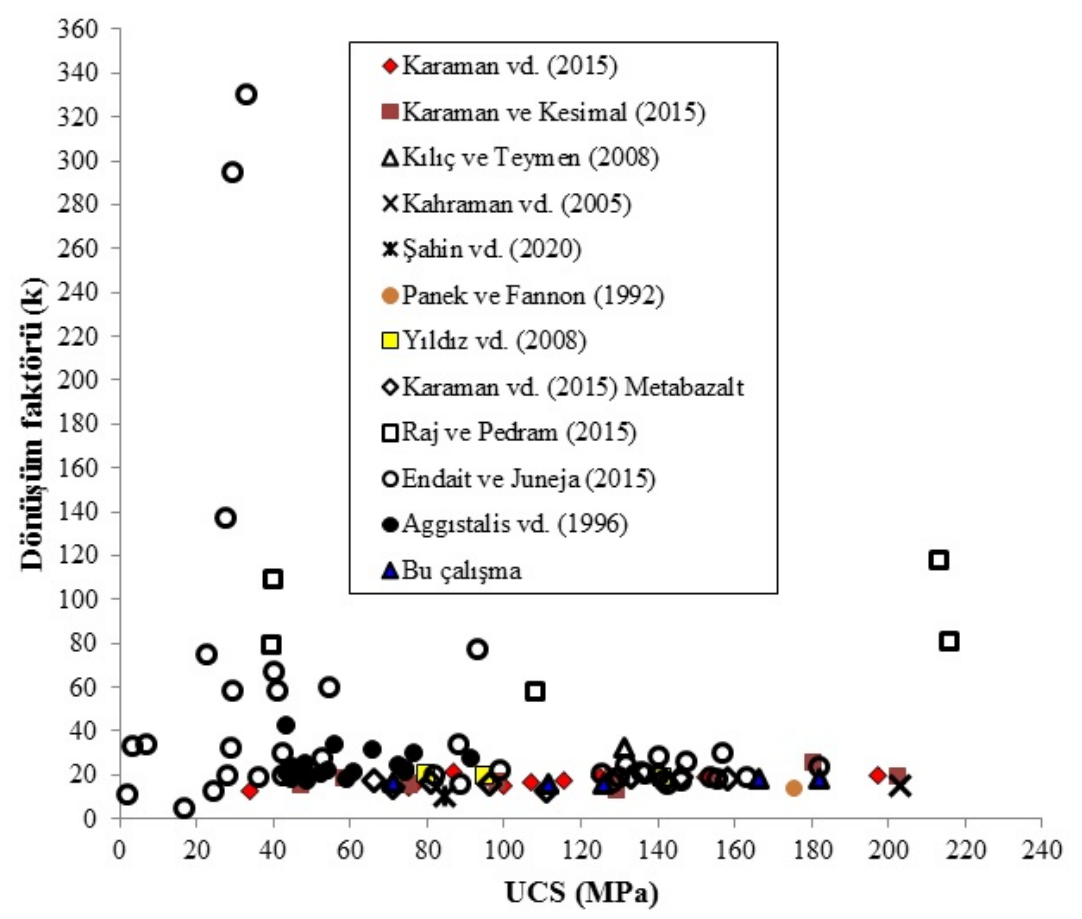

Şekil 3. Dönüşüm faktörü (k) ve UCS arasındaki ilişki

$\mathrm{P}=1.0$ olduğunda ise gruplar birbirine tamamen benzerdir anlamı çıkmaktadır.

$\mathrm{Bu}$ çalışmada varyansların homojenlik testine göre $\mathrm{P}$ değeri $0.000<0.05$ olduğundan grupların varyansları homojen değildir. ANOVA tablosuna göre ise $\mathrm{P}=0.000$ yani $<0.05$ olduğundan gruplar arasında fark vardır. Veriler homojen olmadığ 1 için Post. Hoc. Testlerinden Tamhane testi yapılmıştır (Tablo 4). Literatür taramasina göre bazaltlara ait $\mathrm{k}$ değerlerinin çoğunlukla 15-25 arasında değiştiği görülmüştür. $\mathrm{Bu}$ nedenle söz konusu aralıktaki k değerleri kullanılarak tahmini UCS değerleri elde edilmiştir. Laboratuvarda ölçülen UCS değerlerinin (84 adet) kontrol olarak kullanıldığ 1 Tamhane testine göre $\mathrm{k}$ katsayısı 24 alındığında ölçülen UCS değerlerine benzemediği ve tamamen farklı olduğu sonucu $(\mathrm{P}<0.05)$ ortaya çıkmıştır. $\mathrm{k}$ katsayıları 15 ve 23 alındığında ise Tamhane testine göre benzerlik gösterse de diğer katsayılara göre benzerlik oranı çok düşüktür $(\mathrm{k}=15$ için $\mathrm{P}=0.206$ ve $\mathrm{k}=23$ için $\mathrm{P}=0.221$ ). ANOVA analizleri nokta yükü indeksinden bazaltların tek eksenli basınç dayanımını belirlemek için kullanılması gereken k katsayılarının 16-22 aralığında değişebileceğini göstermiştir. Ayrıca, UCS değerleri ile tahmini UCS değerlerinin birebir örtüştüğü durum k katsayılarının 17-20 aralığında olduğu durumdur. $\mathrm{Bu}$ çalışmadan elde edilen $\mathrm{k}$ katsayısının (17.1) önerilen değerler içinde olduğu görülmüştür. Tek bir değer vermek gerekirse ölçülen ve tahmini UCS değerleri arasındaki ortalama farkın en düşük olduğu k değeri olan 19 sayısı önerilebilir. Ölçülen ve tahmini UCS ortalamalarının karşılaştırılmasını içeren Şekil 4 'teki grafik bu durumu desteklemektedir. Bu çalışmada aynı tür kaya için bile tek bir $\mathrm{k}$ katsayısının olmadığı, buna rağmen tek tip kaya çalışıldığ 1 için $\mathrm{k}$ değerlerinin oldukça yakın bir aralıkta değiştiği anlaşılmıştır. Bazaltların kendi içinde oldukça geniş bir dağılım (vesiküler, amigloidal, olivin ojitli vb.) göstermesi $\mathrm{k}$ oranlarının nispeten değişimine neden olduğu düşünülmüştür. Ayrıca, Akbay ve Altındağ (2020) PLI değerlerindeki değişimlerin test cihazına ve test yöntemine bağlı olabileceğini kapsamlı literatür incelemesi ile ortaya koymuşlardır.

\section{Sonuçlar}

$\mathrm{Bu}$ çalışmada ve literatürden derlenen bazaltlara yönelik toplam 108 adet UCS ve PLI veri çifti değerlendirilmiştir. Dönüşüm faktörlerinin genellikle 15-25 arasında değiştiği görülmüştür. Bazaltların dayanım tahmininde kullanılacak dönüşüm faktörü (k) bu çalışmada kullanılan bazaltlar için 17.1 olarak bulunmuştur. ANOVA analizlerine göre PLI parametresinden bazaltların UCS parametresini tahmin etmek için kullanılması gereken en uygun $\mathrm{k}$ oranının $17 \leq \mathrm{k} \leq 20$ olmas1 gerektiği tavsiye edilmiştir. Önerilen $\mathrm{k}$ değerinin tek bir değer olmamasının en önemli nedenleri; bazaltların çok çeşitli (olivinli, ojitli, zeolitli bazalt, vesiküler bazalt, amigloidal bazalt vb.) jeolojik türlerinin olması, dayanım ve porozite özelliklerinin çok değişken olmasıdır. Tek bir değer vermek gerekirse ANOVA sonuçlarına göre $\mathrm{k}$ değerinin 19 olması uygun olacaktır. 
Tablo 4. Ölçülen ve tahmini UCS değerlerinin çoklu karşılaştırılması

\section{Tamhane}

(I) (J) Ortalama fark Standart Anlamlılık 95\% Güven aralığı

\begin{tabular}{|c|c|c|c|c|c|c|}
\hline Faktör & Faktör & $(\mathbf{I}-\mathbf{J})$ & hata & seviyesi & Alt sınır & Üst sınır \\
\hline \multirow[t]{10}{*}{ UCS } & $\mathrm{k}=15$ & 19.78571 & 6.81019 & 0.206 & -3.1786 & 42.7500 \\
\hline & $\mathrm{k}=16$ & 14.33333 & 7.01039 & 0.908 & -9.3000 & 37.9667 \\
\hline & $\mathrm{k}=17$ & 8.78571 & 7.21667 & 1.000 & -15.5406 & 33.1120 \\
\hline & $\mathrm{k}=18$ & 3.20238 & 7.42499 & 1.000 & -21.8268 & 28.2316 \\
\hline & $\mathrm{k}=19$ & -2.40476 & 7.64377 & 1.000 & -28.1749 & 23.3654 \\
\hline & $\mathrm{k}=20$ & -7.94048 & 7.86358 & 1.000 & -34.4575 & 18.5765 \\
\hline & $\mathrm{k}=21$ & -13.51190 & 8.09532 & 0.996 & -40.8185 & 13.7947 \\
\hline & $\mathrm{k}=22$ & -19.03571 & 8.32509 & 0.730 & -47.1271 & 9.0557 \\
\hline & $\mathrm{k}=23$ & -24.65476 & 8.55765 & 0.221 & -53.5420 & 4.2325 \\
\hline & $\mathrm{k}=24$ & $-30.16667^{*}$ & 8.79583 & 0.042 & -59.8703 & -0.4630 \\
\hline
\end{tabular}

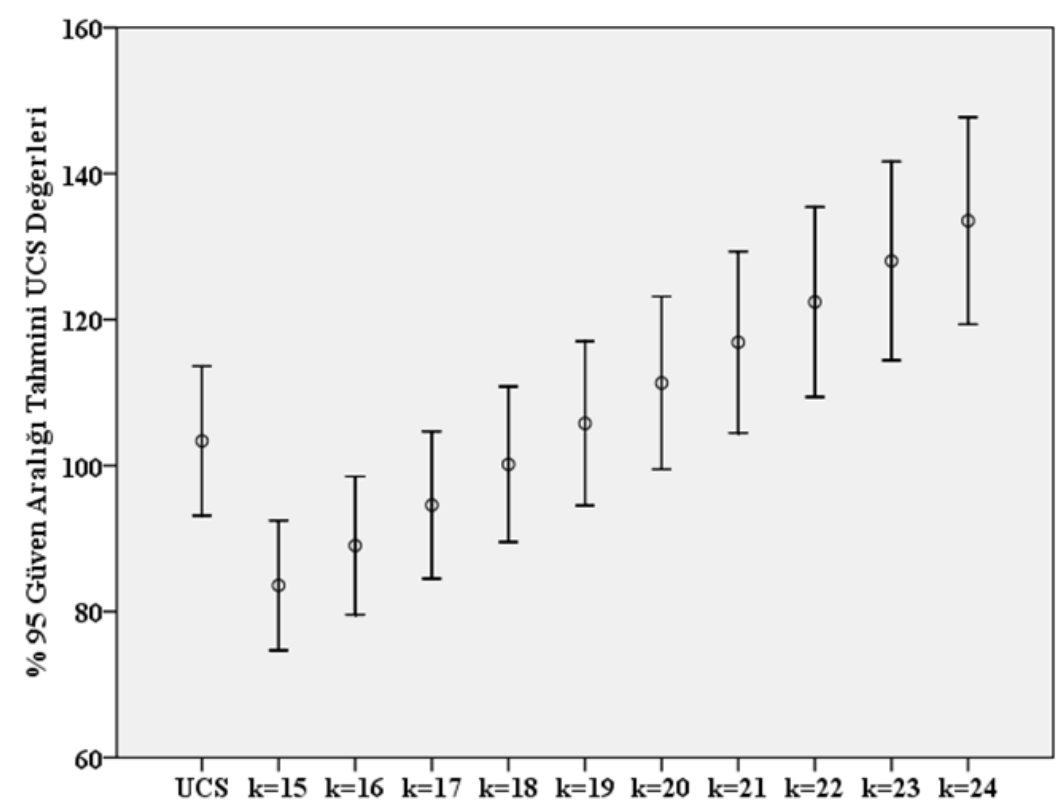

Şekil 4. Ölçülen ve tahmini UCS ortalamalarının karşılaştırılması

\section{Kaynaklar}

Aggistalis, G., Alivizatos, A., Stamoulis, D. and Stournaras, G. (1996). Correlating uniaxial compressive strength with schmidt hardness, point load index, young's modulus, and mineralogy of gabbros and basalts (northern Greece). Bulletin of the International Association of Engineering Geology, 54(1), 3-11. https://doi.org/10.1007/BF02600650

Akbay D. and Altındağ, R. (2020). Reliability and evaluation of point load index values obtained from different testing devices. Journal of the Southern African Institute of Mining and Metallurgy, $\quad 120(3), \quad 181-190$, http://dx.doi.org/10.17159/2411-9717/759/2020
Bieniawski., Z.T. (1975). The point-load test in geotechnical practice. Engineering Geology, $9(1), \quad 1-11$. https://doi.org/10.1016/00137952(75)90024-1

Broch, E. and Franklin, J.A. (1972). The point-load strength test. International Journal of Rock Mechanics and Mining Sciences \& Geomechanics Abstracts, 9(6), 669-676. https://doi.org/10.1016/0148-9062(72)90030-7

D'Andrea, D.V., Fisher, R.L. and Fogelson, D.E. (1964). Prediction of compression strength from other rock properties. Colorado School of Mines, 59(4b), 623-640. 
Dunnett, C.W. and Tamhane, A.C. (1992). A step-up multiple test procedure. Journal of the American Statistical Association, 87(417), 162-170. https://doi.org/10.1080/01621459.1992.1047518 8

Endait, M. and Juneja, A. (2015). New correlations between uniaxial compressive strength and point load strength of basalt. International Journal of Geotechnical Engineering, 9(4), 348-353. http://dx.doi.org/10.1179/1939787914Y.000000 0073

Fener, M., Kahraman, S., Bilgil, A. and Gunaydin, O. (2005). A comparative evaluation of indirect methods to estimate the compressive strength of rocks. Rock Mechanics and Rock Engineering, 38(4), 329-343. https://doi.org/10.1007/s00603005-0061-8

ISRM, (2007). The complete ISRM suggested methods for rock characterization, testing and monitoring: 1974-2006. In: Ulusay, Hudson (Eds.), suggested methods Prepared by the Commission on Testing Methods, International Society for Rock Mechanics. ISRM Turkish National Group, (pp. 628). Ankara, Turkey.

Kahraman, S. (2001). Evaluation of simple methods for assessing the uniaxial compressive strength of rock. International Journal of Rock Mechanics and Mining Sciences, 38(7), 981-994. https://doi.org/10.1016/s1365-1609(01)00039-9

Kahraman, S., Gunaydin, O. and Fener, M. (2005). The effect of porosity on the relation between uniaxial compressive strength and point load index. International Journal of Rock Mechanics and Mining Sciences, 42(4), 584-589. https://doi.org/10.1016/j.ijrmms.2005.02.004

Kahraman, S. (2014). The determination of uniaxial compressive strength from point load strength for pyroclastic rocks. Engineering Geology, 170, 3342.

https://doi.org/10.1016/j.enggeo.2013.12.009

Kalayc1, Ş. (2009). SPSS uygulamalı çok değişkenli istatistik teknikleri (4. Bask1). Ankara: Asil Yayın Dağıtım Ltd. Şti.

Karaman, K. and Kesimal, A. (2015). Evaluation of the influence of porosity on the engineering properties of rocks from the eastern Black Sea region: NE Turkey. Arabian Journal of Geosciences, $\quad 8(1), \quad 557-564$. https://doi.org/10.1007/s12517-013-1217-6

Karaman, K., Kesimal, A. and Ersoy, H. (2015à). A comparative assessment of indirect methods for estimating the uniaxial compressive and tensile strength of rocks. Arabian Journal of Geosciences, $\quad$ 8(4), 2393-2403. https://doi.org/10.1007/s12517-014-1384-0
Karaman, K., Kaya, A. and Kesimal, A. (2015b). Use of the point load index in estimation of the strength rating for the RMR system. Journal of African Earth Sciences 106, 40-49. http://dx.doi.org/10.1016/j.jafrearsci.2015.03.00 6

Kaya, A. and Karaman, K. (2015). Utilizing the strength conversion factor in estimation of the uniaxial compressive strength from the point load index. Bulletin of Engineering Geology and the Environment, $\quad 75(1), \quad 341-357$. https://doi.org/10.1007/s10064-015-0721-1

Kılıç, A. and Teymen, A. (2008). Determination of mechanical properties of rocks using simple methods. Bulletin of Engineering Geology and the Environment, 67(2), 237-244. https://doi.org/10.1007/s10064-008-0128-3

Kılıç, A.M., Karakuş, A. ve Keskin, M.Ö. (2003). Diyarbakır yöresi mermerlerinin fiziko-mekanik özellikleri-özgül enerji ilişkisi. Türkiye $I V$. Mermer sempozyumu (MERSEM '2003) Bildiriler Kitabı (pp. 159-171). Afyon, Türkiye.

Okay, A.I. and Şahintürk, O. (1997). Geology of the eastern Pontides. AAPG memoirs 68: regional and petroleum geology of the Black Sea and surrounding region. American Association of Petroleum Geologists, (pp. 291-311). Tulsa, Oklahoma, U.S.A.

Özdemir, E. ve Sarıcı D.E. (2019). Yazıhan (Malatya) bazaltının fiziko-mekanik özellikleri bakımından balast taşı olarak kullanılabilirliğinin incelenmesi. 1. Uluslararast Malatya Uygulamal Bilimler Kongresi (pp. 295-299). Malatya, Türkiye.

Panek, L.A. and Fannon, T.A. (1992). Size and shape effects in point load tests of irregular rock fragments. Rock Mechanics and Rock Engineering, 25(2), 109-140. https://doi.org/10.1007/bf01040515

Parlak, O., Çolakoğlu, A., Dönmez, C., Sayak, H., Türkel, A., Yıldırım, N. and Odabaşı, I. (2013). Geochemistry and tectonic significance of ophiolites along the İzmir-Ankara-Erzincan suture zone in northeastern Anatolia. Geological Society, London, Special Publications, 372(1), 75-105. https://doi.org/10.1144/sp372.7

Pells, P.J.N. (1975). The use of point load test in predicting the compressive strength of rock material Technical note. International Journal of Rock Mechanics and Mining Sciences \& Geomechanics Abstracts, 13(6), 54-56. https://doi.org/10.1016/0148-9062(76)91301-2

Raj, K. and Pedram, R. (2015). Correlations between direct and indirect strength test methods. International Journal of Mining Science and 
Technology, 25(3), 355- 360. https://doi.org/10.1016/j.ijmst.2015.03.005

Read, J.R.L., Thornten, P.N. and Regan, W.M. (1980). A rational approach to the point load test. Proc. 3rd Australian-New Zealand Geomechanics Conference (pp. 35-39). Wellington, New Zealand.

Sharo, A.A. and Al-Tawaha, M.S., (2019). Prediction of engineering properties of basaltic rocks in Jordan. International Journal of Civil Engineering and Technology (IJCIET), 10(1), 1731-1739.

Şahin, M., Ulusay, R. and Karakul, H. (2020). Point load strength index of half-cut core specimens and correlation with uniaxial compressive strength. Rock Mechanics and Rock Engineering, 53(8),
3745-3760. https://doi.org/10.1007/s00603-02002137-9

Singh, T.N., Kainthola, A. and Venkatesh, A. (2012). Correlation between point load index and uniaxial compressive strength for different rock types. Rock Mechanics and Rock Engineering, 45(2), 259-264. https://doi.org/10.1007/s00603011-0192-Z

Topal, T. (2000). Nokta yükleme deneyi ile ilgili uygulamada karşılaşılan problemler. Jeoloji Mühendisliği Dergisi, 24(1), 73-86.

Yıldız, S., Işık, N. ve Keleştemur, O. (2008). Diyarbakır-Karacadağ bazalt taşlarının mekanik özelliklerinin incelenmesi. Firat Üniviversitesi Fen ve Mühendislik Bilimleri Dergisi, 20(4), 617-626. 